\title{
EVOLUÇÃO PARAGENÉTICA E DOS FLUIDOS NO DEPÓSITO EPITERMAL CUPRO-AURÍFERO GOLDEN HILL, CAMAGUEY, CUBA
}

\author{
MERCEDES TORRES LA ROSA ${ }^{1 *}$, ROBERTO PEREZ XAVIER ${ }^{1}$ \& RENÉ LUGO PRIMELLES ${ }^{2}$
}

\begin{abstract}
PARAGENETIC AND FLUID EVOLUTION IN THE GOLDEN HILL EPITHERMAL CU-Au DEPOSIT, CAMAGUEY, CUBA The Cu-Au mineralization at the Golden Hill deposit in the Las Tunas Province, Eastern Cuba, is characterized by brecciahosted massive and semi-massive sulfide bodies confined to the Crucero Contramaestre Formation in the Cretaceous Volcanic Arc. The deposit is enveloped by a silicic, argillic and advanced argillic alteration assemblage and the $\mathrm{Cu}-\mathrm{Au}$ orebodies are particularly associated with the latter, typical of high sulfidation epithermal deposits.

Within the advanced argillic alteration zone, two stages of alteration were defined on the basis of the mineralogical and textural associations: (i) Stage I with quartz-kaolinite-alunite-zunyite-diaspore, disseminated pyrite, enargite and, probably, sub-microscopic Au; (ii) Stage II with quartz - natroalunite - pyrophyllite, closely related to pyrite - enargite - luzonite - famatinite and Au. Barite commonly occurs filling fractures and cavities and may have been introduced late during Stage II. These assemblages indicate that, in both stages, the advanced argillic alteration and the $\mathrm{Cu}-\mathrm{Au}$ mineralization took place under conditions of low $\mathrm{pH}(<3)$, high redox state $\left(f O_{2}>10^{-32.8}\right.$ bar) and high $\mathrm{SO}_{4} / \mathrm{H}_{2} \mathrm{~S}$ ratios, with $f \mathrm{~S}_{2}>10^{-9.7}$ bar and $f \mathrm{~S}_{2}>10^{-8.7}$ bar for stages I and II, respectively. Additionally, temperatures for the stage I were constrained between $250^{\circ} \mathrm{C}$ and $275^{\circ} \mathrm{C}$, based on the coexistence of alunite-woodhouseite and quartz-kaolinite-diaspore, whereas for stage II they varied from $188^{\circ} \mathrm{C}$ and $330^{\circ} \mathrm{C}$, according to the total homogenization temperatures of fluid inclusions in quartz and the stability of pyrophyllite-bearing assemblages. Fluid inclusion investigations, restricted to stage II quartz and barite, revealed that part of the advanced argillic alteration and the Cu-Au mineralization took place in the presence of $\mathrm{CO}_{2}$ - poor $(<0.85$ molal $)$, low, but variable, salinity $(0,5-9,3 \mathrm{wt} \% \mathrm{eq}$. $\mathrm{NaCl})$ aqueous solutions.

The presence of $\mathrm{CO}_{2}$ and the ample interval of salinity and total homogenization values of the inclusion fluids, together with $\mathrm{W}$ and Bi-Mo-bearing minerals in Stage II, are evidence to envisage the hydrothermal system of the Golden Hill deposit as a result of a progressive interaction of more diluted and lower temperature surface fluids, with more saline and higher temperature magmatic solutions. This would imply in possibilities of the occurrence of shallow epizonal intrusions, which are generally considered important sites for porphyry $\mathrm{Cu}-\mathrm{Au}$ mineralization.
\end{abstract}

Keywords: Golden Hill, epithermal deposits, high sulphidation, advanced argillic alteration, fluid inclusions.

Resumo O depósito Golden Hill, na Província Las Tunas, Cuba oriental, localiza-se no Arco Vulcânico Cretácico onde corpos de sulfeto maciço e semi-maciço estão hospedados em brechas com clastos de andesito, traquiandesito, andesito-basalto e tufos da Formação Crucero Contramaestre. A alteração hidrotermal inclui a silícica, argílica e argílica avançada, típicas de depósitos epitermais de alta sulfetação. Os corpos de minério sulfetado gradacionam em superfície para zonas oxidadas de natureza supergênica.

A mineralização cupro-aurífera primária concentra-se na zona de alteração argílica avançada onde dois estágios hidrotermais foram diferenciados com base na associação mineralógica e relações texturais: (i) Estágio I, com quartzo-caolinita-alunita-zunyita-diásporo, pirita disseminada, enargita e, possivelmente, ouro submicroscópico; (ii) Estágio II com quartzo-natroalunita-pirofilita associada com pirita-enargita-luzonita-famatinita e ouro. A barita preenche fraturas e cavidades e formou-se nos períodos mais tardios do estágio II.

Essas assembléias indicam que a alteração argílica avançada e a mineralização de Cu-Au ocorreram, em ambos estágios, em ambiente de pH ácido (<3), oxidante $\left(f \mathrm{O}_{2}>10^{-32,8}\right.$ bar) e com razões $\mathrm{SO}_{4}^{-} / \mathrm{H}_{2} \mathrm{~S}$ elevadas, sendo $f \mathrm{~S}_{2}>10^{-9,7}$ bar para o estágio I e $f \mathrm{~S}_{2}>10^{-8.7}$ bar para o estágio II. Ademais, as assembléias alunita-woodhouseita e quartzo-caolinita-diásporo sugerem que o intervalo de temperatura do fluido no estágio I deve ter sido entre $250^{\circ} \mathrm{C}$ e $275^{\circ} \mathrm{C}$, e no estágio II entre $188^{\circ} \mathrm{C}$ e $330^{\circ} \mathrm{C}$, com base nas temperaturas de homogeneização total de inclusões fluidas em quartzo e da estabilidade de assembléias com pirofilita. Estudos de inclusões fluidas em quartzo e barita do estágio II também revelam que parte da alteração argílica avançada e da mineralização de Cu-Au ocorreram na presença de fluidos aquosos, de salinidade baixa e variável $(0,5$ a $9,3 \%$ peso equivalente de $\mathrm{NaCl})$, pobre $\mathrm{em}^{\mathrm{CO}}(<0,85 \mathrm{molal})$.

A presença de $\mathrm{CO}_{2}$ nas inclusões fluidas, variações da salinidade e das temperaturas de homogeneização total e a ocorrência de minerais com W e Bi-Mo no estágio II constituem-se possíveis evidências da interação progressiva de fluidos meteóricos, mais diluídos e frios, com soluções magmáticas salinas e mais quentes no sistema hidrotermal. Nesse contexto, pode-se sugerir a possível ocorrência de intrusões epizonais em profundidade, que seriam metalotectos para mineralização de Cu-Au-pórfiro.

Palavras-chave: Golden Hill, depósitos epitermais, alta sulfetação, alteração argílica avançada, inclusões fluidas.

INTRODUÇÃO O setor centro-oriental de Cuba tem sido objeto de vários estudos orientados à definição de seu arcabouço geológico, com implicações na prospeç̧ão de depósitos de $\mathrm{Cu}-\mathrm{Au}$ epitermais, $\mathrm{Au}-\mathrm{Fe}$ em escarnitos e $\mathrm{Cu}-\mathrm{Mo}$ do tipo pórfiro (Shevshenko et al.1976, Ovchinikov et al. 1983, Velinov et al. 1983, Cabrera et al. 1984, Echevarría et al. 1986, Escobar et al. 1988,

1 - Departamento de Geología e Recursos Naturais, Instituto de Geociências - UNICAMP - Caixa Postal 6152, 13.083-970 - Campinas-SP. E-mail: xavier@ige.unicamp.br

2 - MacDonald Mines Exploration Ltd., Geominera S.A., Camaguey, Cuba

* Endereço atual: Instituto de Geologia e Paleontologia de Cuba, Gaveta Postal 370, Habana 10 100, C., Habana, Cuba

Correspondência deve ser enviada ao segundo autor. 
Kramer et al. 1990) (Fig. 1). As unidades geotectônicas deste setor incluem a Plataforma das Bahamas com sequiências de rochas sedimentares de margem continental de idade Jurássica, arcos vulcânicos e complexos ofiolíticos de idade Cretácica e Paleógena, recobertos discordantemente por rochas sedimentares do Eoceno Superior ao Recente (Iturralde 1994).

Como resultado de um programa de exploração para Au e metais base desenvolvido em 1992, pela MacDonald Ltd., do Canadá, e a Geominera S.A., de Cuba, os depósitos da região de CiegoCamagiiey-Las Tunas foram reavaliados e novas ocorrências encontradas. Como destaque deste programa tem-se a descoberta do depósito Golden Hill, com mineralização epitermal de $\mathrm{Cu}-\mathrm{Au}$.

Melling (1998), a partir de estudos mineralógicos, geoquímicos e de alteração hidrotermal, classificou o depósito como do tipo alta sulfetação, com a mineralização geneticamente associada a zonas de alteração argílica avançada, sugerindo uma possível relação genética com intrusões epizonais, portadoras de cobre do tipo pótfiro.

No presente trabalho, estudos mineralógicos e texturais da zona de alteração argílica avançada e mineralização associada, conjuntamente com microtermometria e micro-espectroscopia Raman de inclusões fluidas, foram desenvolvidos para reconstruir o ambiente físico-químico de precipitação de $\mathrm{Cu}$ e $\mathrm{Au}$ no depósito Golden Hill, assim como a evolução do fluido mineralizante.

\section{GEOLOGIA DODEPÓSITO CUPRO-AURÍFERO GOLDEN}

HILL O depósito de Cu-Au Golden Hill é parte do sistema epitermal da região de Ciego-Camaguiey-Las Tunas, Cuba CentroOriental, o qual está espacialmente associado a uma seqüência vulcano-sedimentar e plutônica de arco vulcânico do Cratáceo (Fig. 1). Na evolução do arco, duas etapas de vulcanismo são definidas (Tchounev et al. 1986, apud Echevarría et al. 1986): (1) vulcanismo marinho, localmente de águas rasas, predominando basaltos, traqui-basaltos, traqui-andesitos, andesitos-basaltos e andesitos; (2) vulcanismo subaéreo, explosivo, com tufos, ignimbritos, andesitos-basaltos, andesitos, traquiandesitos, dacitos, riolitos e piroclásticas associadas. O magmatismo intrusivo do arco é representado por granodiorito, granito, gabro, sienito e monzonito.

O depósito de $\mathrm{Cu}-\mathrm{Au}$ Golden Hill situa-se a $8 \mathrm{~km}$ ao N-NE da localidade de Jobabo, Província Las Tunas, (Fig. 1), onde cinco corpos mineralizados foram individualizados, abrangendo uma área de aproximadamente $7,2 \mathrm{~km}^{2}$ : Little Hill, Big Hill, Three Hills, Castle Rock e Raul's Ridge (Fig. 2). As reservas de metal contido nos corpos de minério oxidado e primário foram estimadas em 6,2 toneladas métricas de $\mathrm{Au}$, a um teor entre 1,0 e $2,5 \mathrm{~g} / \mathrm{t}$ de $\mathrm{Au}$, e 21.000 toneladas métricas de $\mathrm{Cu}$, a um teor entre 0,5 e 1,5\% de $\mathrm{Cu}$ (Melling et al. 1996, 1997, apud Melling 1998).

A área do depósito é dominada pela Formação Crucero Contramaestre que consiste de $2800 \mathrm{~m}$ de rochas sedimentares geradas em ambiente marinho e sub-aéreo, incluindo tufos, arenitos tufáceos, arenitos, calcários, rochas silicosas e conglomerados, estes últimos formados pelo transporte de materiais de proveniência vulcânica e piroclástica. Uma série de diques de composição andesítica a traqui-andesítica corta toda Formação Crucero Contramaestre, assim como os corpos de minério e zonas de alteração hidrotermal associadas ao depósito Golden Hill.

As rochas sedimentares de origem marinha da Formação Crucero Contramaestre foram observadas apenas a distâncias de poucos quilômetros, mas não na área do depósito Golden Hill.
As rochas hospedeiras da mineralização de Cu-Au no depósito incluem brechas andesíticas, andesito-basalto e tufos da Formação Crucero Contramaestre, em ambiente de cratera de um paleovulcão (Melling 1998, Pérez et al.1998) (Fig. 2). O vulcanismo foi aparentemente controlado por um sistema de falhas de direção NNW, N-S e NE, também conhecido como Trend Golden Hill, o qual deve ter favorecido a circulação de fluidos hidrotermais e a deposição de Cu e Au (Melling 1998).

A mineralização de $\mathrm{Cu}$-Au do depósito concentra-se em lentes de sulfeto maciço com espeśsura entre 25 e $40 \mathrm{~m}$. Estes corpos possuem extensão de algumas centenas de metros, podendo alcançar profundidades de até $40 \mathrm{~m}$ ao longo do mergulho de 40 a $60^{\circ} \mathrm{SE}$ (MacDonald Exploration Ltd 1996, 997, apud Capote 1999). A alteração hidrotermal associada ao depósito Golden Hill é abrangente, com assembléias típicas de depósitos de alta sulfetação, formada por alteração silícica, argílica e argílica avançada, que substituem uma alteração propilítica anterior (Green 1996).

A alteração silícica manifesta-se pela intensa silicificação das rochas vulcânicas hospedeiras, particularmente em brechas andesíticas, e formação de geodos de quartzo na parte superior do sistema hidrotermal. A alteração argílica é intermediária à zona argílica avançada, sendo que esta última é a que envolve os corpos auríferos sulfetados do depósito Golden Hill.

Em superfície, ocorre uma zona oxidada formada por processos supergênicos que atinge profundidades entre 15 e $60 \mathrm{~m}$, sendo constituída por limonita terrosa friável e pulverulenta, envolta por domínios com quartzo, caolinita e jarosita subordinada.

MATERIAIS E MÉTODOS O estudo dos minerais e da paragênese da alteração argílica avançada e o de inclusões fluidas foram realizados a partir das amostras do minério primário e rochas encaixantes coletados em afloramentos (14 amostras) e furos de sondagem (80 amostras; furos GH 16, GH 135 e GH 64, Fig, 2). Estas amostras foram sistematicamente investigadas ao microscópio petrográfico convencional, com apoio de análises de Microscopia Eletrônica de Varredura (MEV), utilizando-se equipamento modelo LEO 430i (Cambridge/Leica), com espectrômetro de energia dispersiva CatB.

$O$ estudo de inclusões fluidas foi direcionado para definir a composição química e temperatura dos fluidos envolvidos na alteração hidrotermal e mineralização, incluindo possíveis tendências evolutivas. Para o desenvolvimento deste estudo foram selecionadas 12 amostras de quartzo (veios, geodo e matriz da brecha) e barita (veio e bolsão). A microtermometria e microespectroscopia Raman foram desenvolvidas em lâminas com aproximadamente $50 \mu \mathrm{m}$ de espessura, polidas em ambas as faces. Os dados de microtermometria foram obtidos em uma platina de resfriamento/aquecimento Linkam THMSG-600, acoplada a um microscópio petrográfico convencional, sendo a sua calibração efetuada com o auxílio de um conjunto de inclusões sintéticas padrões, manufaturadas pela SYN FLINC. As temperaturas de mudanças de fase registradas foram fusão do gelo (Tfg) e de homogeneização total (Th, ), com precisões de $\pm 0,1^{\circ} \mathrm{Ce} \pm 3^{\circ} \mathrm{C}$, respectivamente. Os dados da microtermometria foram complementados com análises efetuadas na fase vapor dessas inclusões, com o objetivo de se detectar a possível presença de voláteis dissolvidos. Essas análises foram realizadas com um sistema de micro-espectroscopia Raman JOBIN-YVON, modelo T64000, utilizando-se fonte de laser de argônio, com irradiação na linha $514,5 \mathrm{~nm}$ e intensidade de $600 \mathrm{~mW}$, durante $300 \mathrm{~s}$, para cada composto considerado. Esses estudos foram desenvolvidos no 


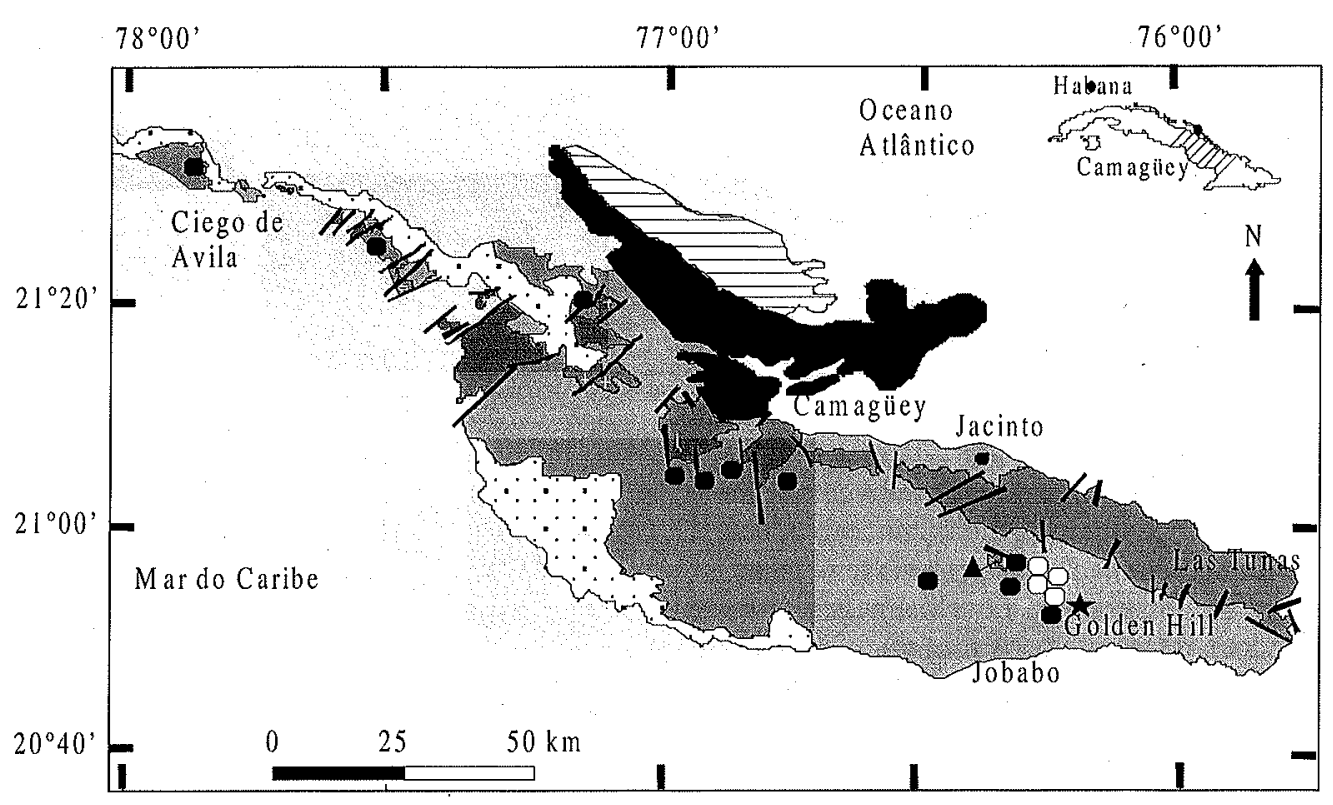

LEGENDA
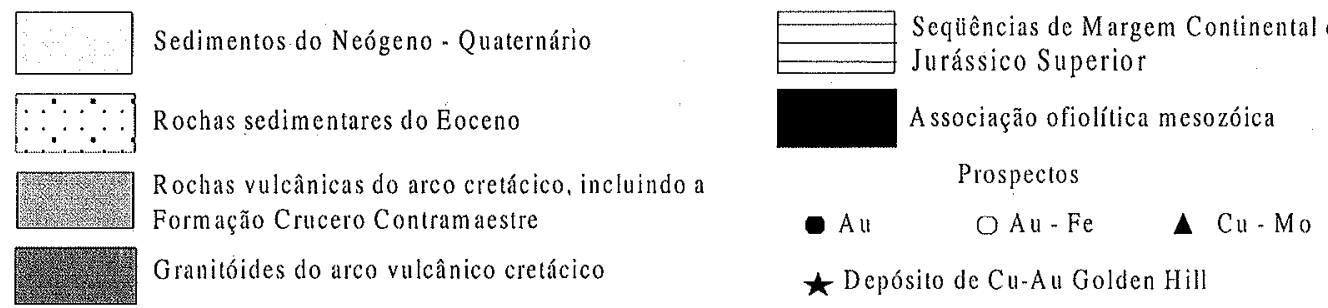

Figura 1 - Mapa geológico da região de Ciego-Camagüey-Las Tunas, setor centro oriental de Cuba, com a localização do depósito de Cu-Au Golden Hill (modificado de Pérez \& Sukar 1997).

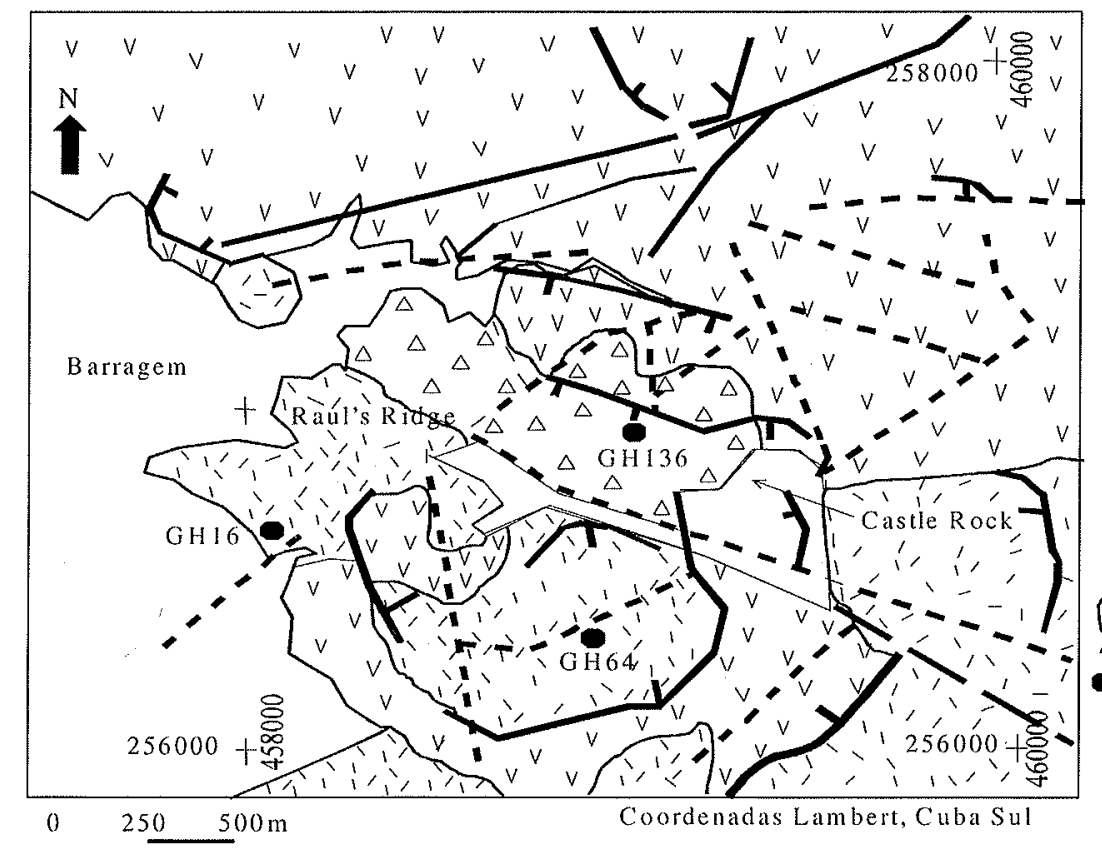

LEGEN DA

Cretáceo Superior

1, i Lavas e tufos ácidos

\begin{tabular}{|l|l}
$\Delta \Delta \Delta$ \\
$\Delta \Delta \Delta$
\end{tabular} Brechas andesíticas

Cretáceo Inferior

$\checkmark \vee \vee \vee$ Andesitos e basaltos

Falhas de alto angulo $\left(>45^{\circ}\right)$

antiga recente

Contatos litológicos

- Furos de sondagem

GH64 - Three Hill

GH16 - Little Hill

GH136- Big Hill

Figura. 2 - Mapa geológico do depósito Golden Hill, com a localização dos principais corpos de minério (modificado de Capote 1999). 
Instituto de Geociências da Universidade Estadual de Campinas.

ALTERAÇÃOARGÍLICA AVANÇADA A assembléia de alteração argílica avançada é formada por quartzo, caolinita, alunita, zunyita, diásporo e pirofilita, sendo a pirofilita e a zunyita comuns em Big Hill e Three Hill, enquanto que em Little Hill a pirofilita é escassa e a zunyita ausente.

Com base na associação mineralógica e relações texturais foram identificados dois estágios de alteração hidrotermal no desenvolvimento da alteração argílica avançada:

Estágio I Écaracterizado por quartzo-caolinita-alunita-zunyitadiásporo e rutilo. O quartzo ocorre formando agregados com grãos variando de $40 \mathrm{a} 760 \mu \mathrm{m}$, às vezes intercrescidos com caolinita $\mathrm{e}$ em conjunto, substituem completamente a assembléia mineral original das rochas vulcânicas hospedeiras. Localmente, essas rochas ainda preservam relictos da textura porfirítica original, embora os fenocristais de feldspatos já se encontrem substituídos por caolinita e sericita (Fig 3A).

Alunita ocorre nas bordas dos fenocristais caolinizados e sericitizados ou, mais subordinadamente, como disseminações na matriz das rochas vulcânicas hospedeiras. A zunyita ocorre em grãos tetraédricos, isolados ou em agregados no interior de massas de quartzo-alunita. Diásporo, em grãos com dimensões variáveis entre 50 e $210 \mu \mathrm{m}$, ocorrem em contato com quartzo e mostram evidências de cristalização contemporânea. O rutilo geralmente aparece disperso na matriz formando conjuntos de agregados de grãos euédricos. A dickita, polimorfo de caolinita, ocorre em finas lâminas associadas a alunita.

Ainda no estágio I foram identificados woodhouseita, um alumino-fosfo-sulfato do grupo da beudantita, e florencita, um alumino-fosfato do grupo da crandalita, em grãos euédricos a subédricos, com dimensões entre 3,5-120 $\mu \mathrm{m}$, em associação com quartzo e pirita na matriz da brecha andesítica silicificada. Análises por MEV nesses minerais indicam a presença de $\mathrm{Sr}, \mathrm{Ca}$ e $\mathrm{P}$, na woodhouseita, enquanto que a florencita, além de Sr, contém elementos de terras raras.

Estágio II Caracteriza-se pela assembléia quartzo - natroalunitapirofilita que substitui os minerais de alteração do estágio I. O quartzo e a pirofilita, esta última em quantidades que variam de 3 a $35 \%$, formam massas microcristalinas e vênulas que substituem ou cortam a assembléia de alteração do estágio I. A natroalunita desenvolve-se nas bordas da woodhouseita, ou como finas lâminas dispersas no interior dos grãos deste mineral, como também o penetra sob a forma de vênulas, indicando um processo de substituição (Fig. 3B).

Barita e gipsita são fases tardias da alteração argílica avançada e de ocorrência comum no depósito. A primeira preenche cavidades no minério com deposição posterior ao quartzo do estágio II e forma bolsões isolados, enquanto a segunda ocorre principalmente em veios.

PARAGÊNESEDOMINÉRIOEASPECTOSTEXTURAIS Pirita e enargita são os minerais de minério predominantes no depósito e quando ocorrem em concentrações superiores a $50 \%$ definem corpos de sulfeto maciço, enquanto que em concentrações $<45 \%$ os corpos de minério são denominados de semimaciço, não havendo minério disseminado.

Nos corpos de sulfeto maciço a pirita contribui com 50 a $95 \%$ e a enargita ocorre comumente em concentrações subordinadas entre
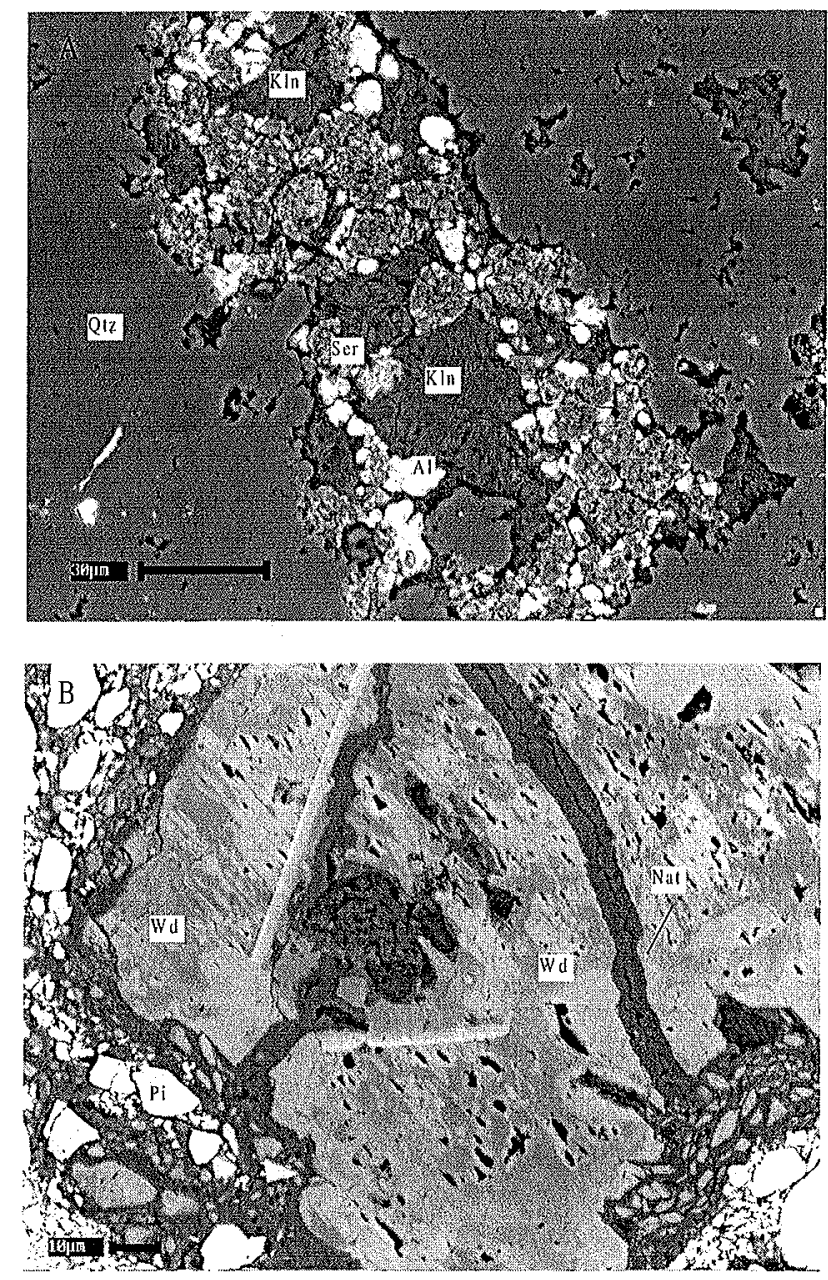

Figura 3 - Fotomicrografias ilustrando as relações paragenéticas dos minerais de alteração argílica avançada do depósito de Golden Hill. A) Relictos de fenocristais de feldspato em clastos andesíticos dos tufos, substituidos por caolinita do estágio $I ; B$ ) Woodhouseita do estágio I substituída nas bordas por natroalunita do estágio II. Símbolos: $K l n=$ caolinita, $N a t=$ natroalunita, $P i=$ pirita, $Q t z=$ quartzo, Ser $=$ sericita $e \mathrm{Wd}=$ woodhouseita. O comprimento das barras é de $10 \mu \mathrm{m}$.

0,1 e $10 \%$ embora, localmente, até $45 \%$ em volume.

Com base na associação mineralógica e relações texturais, a seqüência de deposição de sulfetos nos corpos de minério maciço e semimaciço do depósito Golden Hill também pode ser vinculada aos estágios I e II de alteração argílica avançada.

Estágio I Écaracterizado pela assembléia pirita-enargita, sendo que a pirita forma estruturas esféricas, com diâmetro entre 15 a 40 $\mu \mathrm{m}$, constituídas por agregados de cristais cúbicos, com dimensões uniformes em torno de $1 \mu \mathrm{m}$, o que lhe confere uma textura framboidal (Fig. 4A). Este tipo de textura é freqüentemente observado no corpo de sulfeto maciço e, apenas localmente, nos de sulfeto semimaciço. A origem de pirita framboidal permanece uma questão em aberto, tendo sido interpretada como de origem orgânica (Schneiderhöhn 1923, Love 1958, Skripchenko 1970, Locquin et al. 1978 apud England \& Ostwald 1993), formada nas sequiências 
piroclásticas durante o estágio tardio de atividade vulcânica, em torno de $280^{\circ} \mathrm{C}$ (Özgür 1985 apud Schneider et al. 1988), ou por substituição de vacúolos das lavas (Rickard 1970). Neste trabalho, a matéria orgânica não foi observada em associação com a pirita framboidal, porém a ocorrência de uma seqüência carbonatada com fauna, particularmente em Maclama e La Pala, a $8 \mathrm{~km}$ e $6 \mathrm{~km}$ de Golden Hill, respectivamente indica que houve condições para o seu desenvolvimento no ambiente de arco vulcânico onde se localiza o depósito. A sua não preservação no depósito, no entanto, pode ser atribuída à sua evaporação ou dissolução durante a piritização.

Adicionalmente, a pirita ocorre disseminada, em cristais euédricos com dimensões entre 10 e $150 \mu \mathrm{m}$, e também como concreções (i.e. Corpo Three Hill). Essas concreções são constituídas por agregados de cristais de pirita pouco agrupados e intercrescidos com quartzo microcristalino, formando subesferas de dimensões de 0,5 a $2 \mathrm{~cm}$ (Fig.4B).

A enargita ocorre em cristais idiomórficos com dimensões de 1 a $2 \mathrm{~mm}$, disseminada entre os cristais euédricos de pirita intercrescidos com quartzo.

Neste estudo, o ouro, no seu estado nativo e como grãos livres, não foi observado no estágio I, possivelmente pelo baixo teor das amostras investigadas (i.e $0,94 \mathrm{~g} / \mathrm{t} \mathrm{Au}$ ) ou pelo fato de o ouro neste estágio ocorrer provavelmente de forma submicroscópica.
Estágio II Écaracterizado pela assembléia pirita-enargita-luzonitafamatinita e Ouro que se encontra melhor representada no sulfeto maciço e pouco desenvolvida no sulfeto semimaciço.

A pirita é compacta e engloba restos de frambóides. A textura compacta é interpretada como produto de um contínuo processo de recristalização sobre frambóides de pirita, conferindo-lhes uma textura em anel, até sua recristalização total. Adicionalmente, a pirita também mostra textura zonada possivelmente por interrupção do crescimento do cristal, textura colomórfica com núcleos circulares de pirita fina a grossa intercrescida e, localmente, textura cataclástica, com os espaços entre os clastos preenchidos por woodhouseita, natroalunita e pirofilita. Estanita, wolframita e rutilo ocorrem como inclusões micrométricas na pirita.

A enargita ocorre como agregados irregulares que englobam frambóides de pirita, ou em finas vênulas, atestando a sua origem tardia em relação à pirita do estágio. I. Porém a enargita pode ser substituída nas bordas por pirita do estágio II (Fig. 4C).

Os polimorfos luzonita-famatinita e sulfossais de Cu-Bi-Mo-Te e, mais raramente, calcopirita, esfalerita e galena ocorrem com muita freqüência como inclusões na enargita.

Grãos livres de ouro nativo, com dimensões entre 1 e $20 \mu \mathrm{m}$, irregulares e arredondados, geralmente associam-se à pirita compacta do estágio II, seja preenchendo cavidades ou em contato brusco com suas bordas (Fig. 4D). A concentração de Ag em
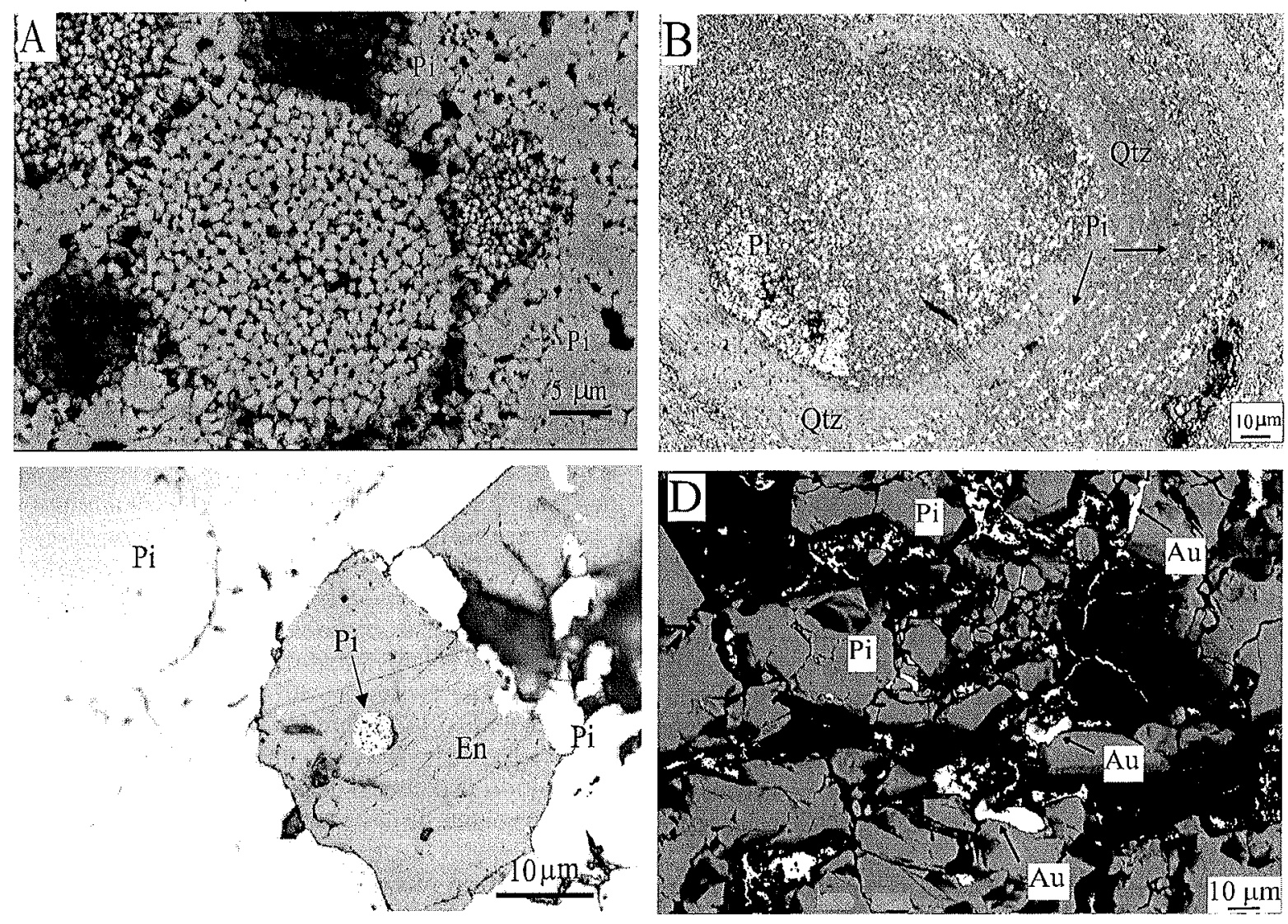

Figura 4 - A) Textura framboidal da pirita do estágio I, com os cristais organizados na forma de cubos; B) Concreções constituídas por agregados de pirita e finas laminações concêntricas de pirita, típicas do estágio I; C) Pirita framboidal englobada em grão de enargita, por sua vez, envolta por pirita compacta que também substitui a enargita nas bordas; D) Grãos de ouro em contato com a pirita do estágio II. Au = ouro. En = enargita, $P i=$ pirita $e Q t z=q u a r t z o$. 
grãos de ouro varia de 15 a $34 \%$.

Teluretos de Au-Ag (Estrugo 1997 comunicação pessoal) e telure to com Fe, determinado em MEV neste trabalho, aparecem como escassos grãos em cavidades da pirita.

A covelita ocorre em agregados finos ao longo das bordas da enargita ou a corta em forma de vênulas, assim como preenche cavidades na pirita, sendo interpretada como de origem supergênica.

Um resumo da sequiência de formação da paragênese de alteração e de minério desenvolvida nos estágios I e II da alteração argílica avançada definidos no depósito Golden Hill é mostrada na Tabela 1.

INCLUSÕESFLUIDAS Tiposemodos de ocorrência Apenas sete amostras de quartzo do estágio II (geodo e matriz da brecha) e uma amostra de barita de formação tardia no estágio II apresentaram populações de inclusões fluidas com dimensões adequadas para o estudo microtermométrico. Devido as suas pequenas dimensões $(<5 \mu \mathrm{m})$, não foi possível obter dados microtermométricos em inclusões fluidas em quartzo do estágio I.

Grande parte das inclusões investigadas nessas amostras é submicroscópica e as maiores, escassas, encontram-se entre 5 e $10 \mu \mathrm{m}$. Com base nos seus modos de ocorrência, as inclusões fluidas foram classificadas em primárias, pseudosecundárias e secundárias, de acordo com os critérios de Roedder (1984).

Considerando as relações de fases observadas à temperatura ambiente $\left(22^{\circ} \mathrm{C}\right)$, as inclusões fluidas investigadas foram agrupadas nas de tipo I, monofásicas aquosas (L), e tipo II, bifásicas aquosas com fase líquida predominante $(\mathrm{L}>\mathrm{V})$; tipo III - inclusões bifásicas aquosas, com fase vapor predominante $(V>L)$.

As inclusões do tipo I foram identificadas em quartzo associado a mineralização sulfetada, quartzo em geodo e em barita. Essas inclusões são as mais frequientes e distribuem-se de forma isolada ou em grupos isolados, com formas irregulares ou arredondadas, sendo interpretadas como de origem primária (Fig. $5 \mathrm{~A}$ ).

Inclusões tipo do II, embora menos frequientes que as do tipo I, também foram identificadas em quartzo e barita, nas mesmas associações. Essas inclusões apresentam geralmente contornos variáveis de cristal negativo e ocorrem isoladas e em grupos, como inclusões primárias (Fig. 5B), ou ao longo de trilhas curtas e arranjos planares intragranulares, típicas de pseudo-secundárias (Fig. $5 \mathrm{C}$ e D). O grau de preenchimento $\left(\mathrm{V}_{\text {líquido }} / \mathrm{V}_{\text {total da inclusão }}\right)$ dessas inclusões é bastante constante, variando de 0,9 a 0,8 . Em quartzo de geodo e associado ao minério ocasionalmente foram observadas fases sólidas no interior das inclusões do tipo II. Esses sólidos são incolores e apresentam forma prismática e sua identificação não foi possível devido ao seu tamanho reduzido.

Inclusões do tipo III, coexistindo com inclusões tipo II, são muito incomuns e foram observadas particularmente em cristais euedrais de quartzo imersos em matriz de quartzo microcristalino em zonas mineralizadas. Este tipo de inclusões aparece com formatos arredondados, em grupos e isoladas, sendo consideradas de natureza primária. $O$ grau de preenchimento nessas inclusões é de 0,2 a 0,4 .

Durante os ensaios microtermométricos na barita problemas de vazamentos e metaestabilidade foram observados. O fenômeno de vazamento foi identificado pelo aparecimento, após a homogeneização total e resfriamento, de uma bolha de ar preta, que acaba preenchendo completamente a inclusão. A metaestabilidade foi constatada quando a bolha de algumas inclusões não mais voltou a nuclear após a homogeneização total,
Tabela 1 - Seqüência de desenvolvimento da paragênese da alteração e do minério nos estágios I e II correspondente à alteração argílica avançada no depósito Golden Hill.

Mineral
$\begin{aligned} & \text { Quartzo } \\ & \text { Calteração argílica avançada }\end{aligned}$
Alunita
Natroalunita
Zunyita
Diásporo
Rutilo
Woodhousita I Estágio II Supergênico
Florencita
Pirofilita
Barita
Gipsita
Pirita
Enargita
Ouro
Teluretos de Au-Ag
Luzonita-Famatinita
Estanita
Wolframita
Galena
Esfalerita
Covelita
Goethita
Jarosita
Hematita

mesmo resfriando-as a baixas temperaturas.

Microtermometria e micro-espectroscopia Raman das inclusões fluidas A homogeneização total (Tht) das inclusões aquosas do tipo II em todas as populações investigadas ocorre invariavelmente na fase líquida. No quartzo associado a mineralização sulfetada, as Tht concentram-se no intervalo de $188^{\circ} \mathrm{C}$ a $330^{\circ} \mathrm{C}$, com uma leve moda em $241^{\circ} \mathrm{C}$ (Fig. 6A), enquanto as temperaturas de fusão do gelo (Tfg) variam de $-1,2^{\circ} \mathrm{C}$ a $-2,7^{\circ} \mathrm{C}$, indicando salinidades de 2 a $4,5 \%$ em peso equivalente de $\mathrm{NaCl}$.

Embora o estudo petrográfico tenha constatado a coexistência de inclusões do tipo II (ricas na fase líquida) e do tipo III (ricas na fase vapor), sugerindo que os fluidos mineralizantes poderiam estar em ebulição durante o aprisionamento, os dados microtermométricos não comprovam a atuação desse processo: (a) as inclusões do tipo III homogeneizam-se para o estado líquido, e não para o vapor, como esperado em um quadro de ebulição; (b) os poucos valores obtidos encontram-se sempre acima de $350^{\circ} \mathrm{C}$ (Fig. $6 \mathrm{~A}$ ). Neste contexto e considerando a sua escassez, as inclusões do tipo III podem ser consideradas como produtos de modificações de inclusões do tipo II, após o seu aprisionamento, particularmente por meio da perda de $\mathrm{H}_{2} \mathrm{O}$, com conseqüente aumento do volume da fase vapor (decréscimo do grau de preenchimento)

No quartzo de geodo as inclusões do tipo II mostram Tht entre $172^{\circ} \mathrm{Ce} 274^{\circ} \mathrm{C}$, com a moda em $198^{\circ} \mathrm{C}$ (Fig. $6 \mathrm{~B}$ ), e Tfg entre $-0,3^{\circ} \mathrm{C}$ e $-6,1^{\circ} \mathrm{C}$, correspondendo a um intervalo mais amplo de salinidade de 0,5 a $9,3 \%$ em peso equivalente de $\mathrm{NaCl}$.

Análises por micro-espectroscopia Raman em várias inclusões dos tipos II em quartzo do minério sulfetado e de geodo do estágio II revelam que a fase vapor de algumas dessas inclusões contém 

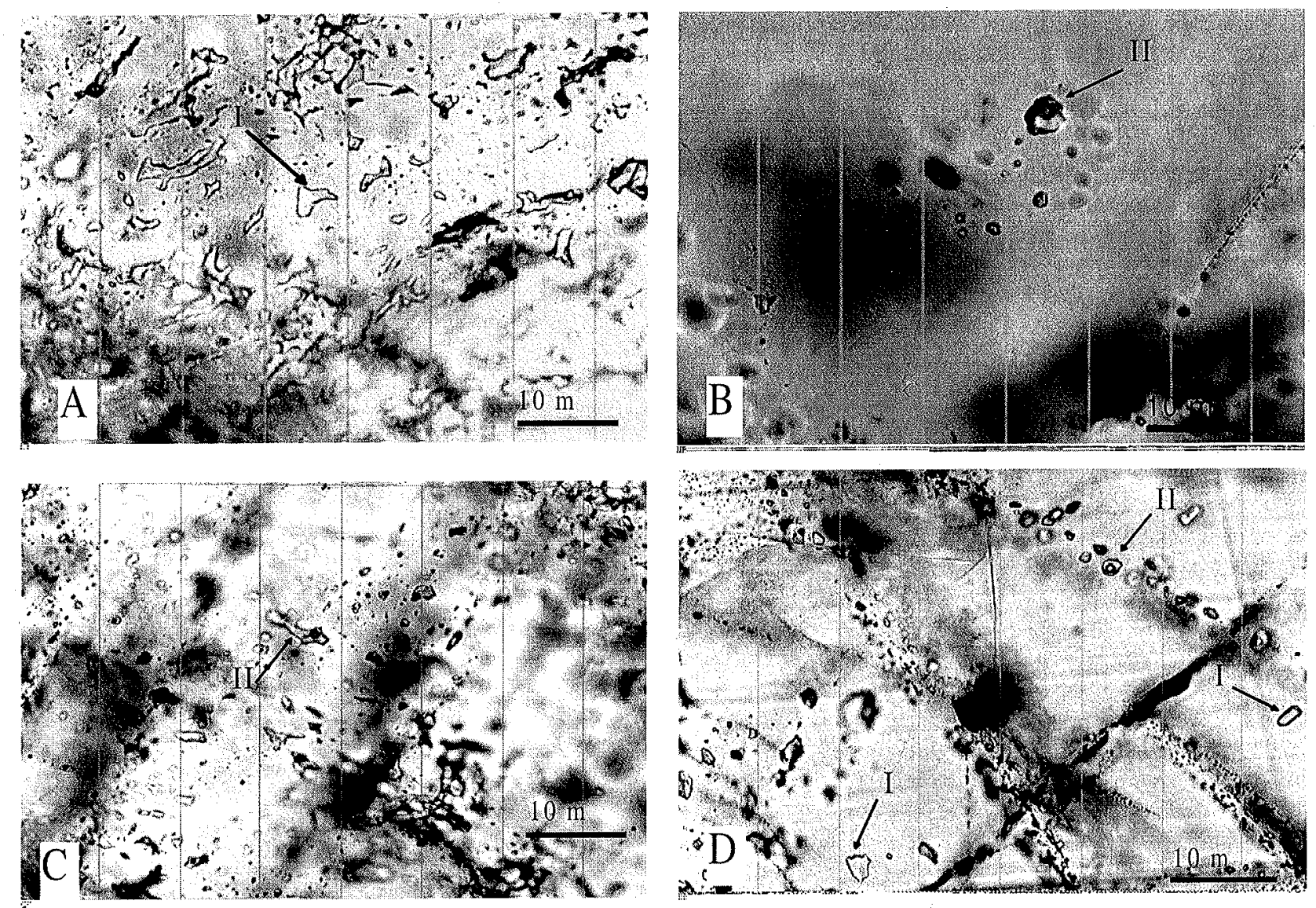

Figura 5 - Modos de ocorrência e tipos de inclusões fluidas investigadas neste trabalho. A) Quartzo de geodo estágio II, contendo inclusões monofásicas aquosas primárias (tipo I); B) Inclusões primárias do tipo II em grupo hospedado por quartzo de geodo; C) Inclusões pseudo-secundárias dos tipos I e II orientadas perpendicularmente às zonas de crescimento do cristal de quartzo de geodo; D) Inclusões pseudo-secundárias e primárias dos tipos I e II ao longo de microfraturas cicatrizadas em barita.

$\mathrm{CO}_{2}$, identificado pela ocorrência nos espectros de picos de baixa intensidade em $1388,2 \mathrm{~cm}^{-1}$ e $1285,0 \mathrm{~cm}^{-1}$. Durante os ensaios microtermométricos não foi observada a nucleação de uma fase de $\mathrm{CO}$ líquido como também a formação de clatratos no resfriamento, o que restringe a valores abaixo de 0,85 molal a concentração de $\mathrm{CO}_{2}$ nos fluidos aquosos do estágio II (Hedenquist \& Henley 1985). A presença de $\mathrm{CO}_{2}$ pode causar um rebaixamento maior nas temperaturas de fusão do gelo e, como consequiência, produzir valores um pouco superestimados da salinidade, como determinado por Hedenquist \& Henley (1985) em depósitos epitermais. Porém, no caso de Golden Hill, considera-se que o efeito do $\mathrm{CO}_{2}$ nos valores de salinidade tenha sido mínimo, devido a sua baixa concentração, e que o rebaixamento das temperaturas de fusão do gelo seja devido principalmente ao $\mathrm{NaCl}$.

A fase sólida presente em algumas inclusões de tipo II nestes tipos de quartzo com sulfeto e de geodo não desaparecem durante o procedimento de homogeneização total, mesmo até $400^{\circ} \mathrm{C}$, indicando que podem ser sólidos aprisionados acidentalmente e não cristais de saturação verdadeiros.

$\mathrm{Na}$ barita, as Tht de inclusões primárias do tipo II encontramse concentradas no intervalo de $220^{\circ} \mathrm{C}$ a $240^{\circ} \mathrm{C}$, com maior concentração em $240^{\circ} \mathrm{C}$, enquanto que valores de Tht entre $160^{\circ} \mathrm{C} \mathrm{e}$ $220^{\circ} \mathrm{C}$, com moda em $210^{\circ} \mathrm{C}$, são típicos das inclusões pseudosecundárias do tipo II (Fig. 6C). Nessas inclusões, as Tfg entre- $2,1^{\circ} \mathrm{Ce}-4,1^{\circ} \mathrm{C}$ forneceram valores de salinidade entre 3,5 a $6,5 \%$ em peso equivalente de $\mathrm{NaCl}$.

DISCUSSÃO Alteração argílica avançada e mineralização As seguintes reações podem ilustrar o desenvolvimento do estágio I da alteração argílica avançada do depósito Golden Hill (Hemley et al. 1969, 1980, Knight 1977):

$\mathrm{KAl}_{3} \mathrm{Si}_{3} \mathrm{O}_{10}(\mathrm{OH})_{2}+4 \mathrm{H}^{+}+2 \mathrm{SO}_{4}^{-2}=\mathrm{KAl}_{3}\left(\mathrm{SO}_{4}\right)_{2}(\mathrm{OH})_{6}+3 \mathrm{SiO}_{2 \mathrm{aq}}(1)$ Sericita Alunita

$3 \mathrm{Al}_{2} \mathrm{Si}_{2} \mathrm{O}_{5}(\mathrm{OH})_{4}+2 \mathrm{~K}^{+}+6 \mathrm{H}^{+}+4 \mathrm{SO}_{4}^{2-}=2 \mathrm{KAl}_{3}\left(\mathrm{SO}_{4}\right)_{2}(\mathrm{OH})_{6}+$ Caolinita Alunita

$$
\mathrm{SiO}_{2 \mathrm{aq}}+3 \mathrm{H}_{2} \mathrm{O}(2)
$$

$\mathrm{CaAl}_{3}\left(\mathrm{PO}_{4}\right)\left(\mathrm{SO}_{4}\right)_{2}(\mathrm{OH})_{6}+6 \mathrm{H}^{+}=\mathrm{Ca}^{+}+3 \mathrm{Al}^{3+}+\mathrm{PO}_{4}^{3-}+2 \mathrm{SO}_{4}^{2-}+$ Woodhouseita

$$
6 \mathrm{H}_{2} \mathrm{O}(3)
$$

Estas reações indicam que na formação da assembléia quartzo-caolinita-alunita-woodhouseita-florencita, o fluido aquoso responsável pelo desenvolvimento do estágio I da alteração argílica avançada era fortemente ácido $\left(\mathrm{pH}<3\right.$ ) e com razões $\mathrm{HSO}_{4}^{-} / \mathrm{H}_{2} \mathrm{~S}$ elevadas (Fig. 7). Esses fluidos ácidos dissolveriam a apatita primária das rochas vulcânicas hospedeiras, liberando íons fosfatos na solução para a precipitação de alumino-fosfo-sulfatos (e.g. woodhouseita; Stoffregen \& Alpens 1987). 
$\mathrm{Na}$ ausência de dados de inclusões fluidas, estima-se que o intervalo de temperatura do fluido no estágio I deve ter sido em torno de $250^{\circ} \mathrm{C}$ e $275^{\circ} \mathrm{C}$, com base nas assembléias alunitawoodhouseita e quartzo-caolinita-diásporo, respectivamente (Fig. 8).

No estágio II, evidências texturais revelam que a formação da pirofilita ocorreu às expensas do quartzo, woodhouseita, zunyita $\mathrm{e}$ diásporo, também sob condições de $\mathrm{pH}$ ácido, por meio das reações:

$$
\begin{aligned}
& \underset{\text { Woodhouseita }}{\mathrm{CaAl}_{3}\left(\mathrm{PO}_{4}\right)\left(\mathrm{SO}_{4}\right)_{2}}(\mathrm{OH})_{6}+\underset{\text { Pirofilita }}{4 \mathrm{SiO}_{2}}=\underset{\mathrm{Al}_{2} \mathrm{Si}_{4} \mathrm{O}_{10}}{(\mathrm{OH})_{2}}+2 \mathrm{SO}_{4}{ }^{2-}+\mathrm{Al}^{3+} \\
& +\mathrm{Ca}^{+}+\mathrm{PO}_{4}^{3-}+2 \mathrm{H}_{2} \mathrm{O}(4) \\
& 2 \mathrm{AlO}(\mathrm{OH})+4 \mathrm{SiO}_{2}=\mathrm{Al}_{2} \mathrm{Si}_{4} \mathrm{O}_{10}(\mathrm{OH})_{2}(5) \\
& \text { Diásporo Pirofilita } \\
& \mathrm{Al}_{12}\left[\mathrm{AlSi}_{5} \mathrm{O}_{10}\right](\mathrm{OHF})_{18} \mathrm{Cl}+12 \mathrm{H}^{+}=\mathrm{Al}_{2} \mathrm{Si}_{4} \mathrm{O}_{10}(\mathrm{OH})_{2}+11 \mathrm{Al}^{3+} \\
& \text { Zunyita } \\
& +\mathrm{H}_{4} \mathrm{SiO}_{4}+\mathrm{Cl}^{-}+12 \mathrm{H}_{2} \mathrm{O}+18 \mathrm{~F}^{-}(6)
\end{aligned}
$$

Ainda durante a alteração no estágio II, a woodhouseita altera-se para natroalunita, segundo a reação:

$\mathrm{CaAl}_{3}\left(\mathrm{PO}_{4}\right)\left(\mathrm{SO}_{4}\right)_{2}(\mathrm{OH})_{6}+\mathrm{K}^{+}+\mathrm{Na}^{+}=(\mathrm{Na}, \mathrm{K}) \mathrm{Al}_{3}\left(\mathrm{SO}_{4}\right)_{2}(\mathrm{OH})_{6}+\cdot$ Woodhouseita

$$
\mathrm{Ca}^{+}+\mathrm{PO}_{4}^{3-}(7)
$$
Natroalunita

Estudos de inclusões fluidas em quartzo e barita revelam que a alteração argílica avançada no estágio II ocorreu na presença de fluidos aquosos, de salinidade baixa e variável $(0,5-9,3 \%$ peso eq. $\mathrm{NaCl}$ ), com $\mathrm{CO}_{2}$ em concentrações $<0,85$ molal e temperatura que oscilou entre $172^{\circ} \mathrm{C} \mathrm{a} 330^{\circ} \mathrm{C}$. Apesar do amplo intervalo, temperaturas superiores às estimadas para o estágio I, provavelmente acima de $280^{\circ} \mathrm{C}$, devem ter sido atingidas para estabilizar assembléias com pirofilita (Watanabe \& Hedenquist 2001) (Fig. 8).

As observações realizadas neste trabalho indicam que no depósito estudado a alteração argílica avançada e a mineralização de $\mathrm{Cu}$ e Au foram contemporâneas. Em ambos estágios de alteração argílica avançada, as paragenêses pirita-enargita no estágio I e pirita-enargita-luzonita-famantita (-galena) no estágio II revelam que a deposição da mineralização ocorreu sob fugacidades de $\mathrm{S}_{2} \mathrm{e}$ de $\mathrm{O}_{2}$ elevadas, porém com valores relativamente mais elevados no estágio II, pela presença da famatinita (Fig. 7).

Natureza do sistema hidrotermal O ambiente hidrotermal associado a depósitos epitermais de alta sulfetação geralmente envolve (Arribas 1995): (1) a circulação convectiva de águas meteóricas aquecidas que incorporam gases magmáticos (e.g. $\mathrm{SO}_{2}, \mathrm{CO}_{2}, \mathrm{HCl}$ ) ascendentes, provenientes de intrusões félsicas epizonais; (2) esses fluidos tornam-se altamente ácidos (e.g. $\mathrm{H}_{2} \mathrm{SO}_{4}$ e $\mathrm{H}_{2} \mathrm{CO}_{3}$ ) e oxidantes ( $>\mathrm{HSO}_{4} / \mathrm{H}_{2} \mathrm{~S}$ ) e promovem, em um primeiro estágio, o desenvolvimento da alteração argílica avançada e sílica residual e, posteriormente, a precipitação do minério de alta sulfetação e ouro.

Tendo como base a natureza e idade das rochas hospedeiras, estilo de alteração hidrotermal, forma de ocorrência do minério, paragênese do minério e composição dos fluidos, o depósito de $\mathrm{Cu}-\mathrm{Au}$ Golden Hill pode ser considerado similar a outros depósitos de alta sulfetação clássicos, tais como Lepanto (Filipinas), Nansatsu (Japão), Rodalquilar (Espanha), La Mejicana (Argentina), El Indio (Chile), e Pueblo Viejo (República Dominicana) (ver referências em Cooke \& Simmons 2000).

Portanto, o modelo apresentado acima para depósitos epitermais de alta sulfetação, com o envolvimento progressivo de fluidos magmáticos e meteóricos pode, a princípio, se adequar ao modo de formação do sistema hidrotermal do depósito de $\mathrm{Cu}$-Au Golden Hill. Por exemplo, a presença de baixas concentrações de $\mathrm{CO}_{2}$ no
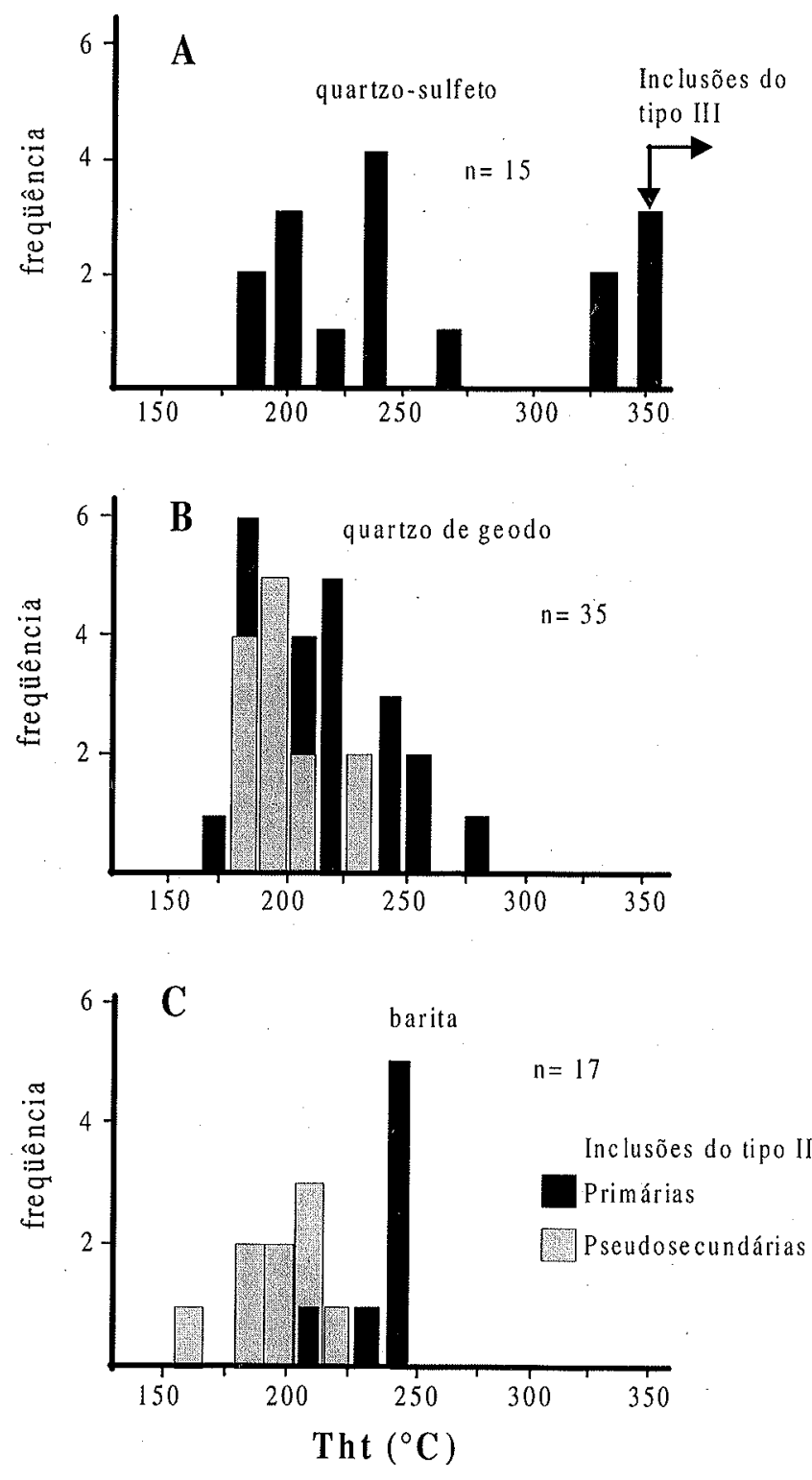

Figura 6-Histogramas mostrando a distribuição da temperatura de homogeneização total (Tht) de inclusões do tipo II em quartzo do estágio II e em barita. p-inclusões primárias, ps-inclusões secundárias, n-número de inclusões analisadas.

fluido e a ocorrência de minerais com W e Bi-Mo no estágio II de mineralização reforça a possível contribuição magmátiça ao sistema hidrotermal do depósito. Adicionalmente, variação na salinidade $(0,5$ a $9,3 \%$ em peso equivalente de $\mathrm{NaCl})$ e temperaturas de homogeneização total das inclusões fluidas investigadas, particularmente em quartzo da mineralização sulfetada $\left(188^{\circ} \mathrm{C}\right.$ a $330^{\circ} \mathrm{C}$ ) do estágio II, também podem se constituir em possíveis evidências da interação progressiva de fluidos meteóricos, mais diluídos e frios, com soluções magmáticas salinas e mais quentes. No entanto, nenhuma correlação entre Tht e salinidade foi observada no estudo de inclusões fluidas que pudesse indicar tendências evolutivas na ação da mistura desses dois tipos de fluidos. As condições físico-químicas de formação da paragênese do minério indicam que complexos do tipo metal-HS seriam as formas 
mais prováveis para o transporte do ouro (e.g. $\mathrm{Au}(\mathrm{HS})_{2}^{-}$ou AuHS $_{(1 \mathrm{l})}$; Benning \& Seward 1996) e cobre(?). Na ausência do processo de ebulição, pelo menos no ambiente da mineralização, e as evidências apresentadas para a mistura de fluidos não serem inequívocas, a interação progressiva de fluidos magmáticos e soluções meteóricas no sistema hidrotermal, é o processo preferencial no caso do depósito Golden Hill para explicar a deposição do ouro e, talvez, cobre. Esse processo pode causar o aumento do potencial de oxidação das soluções, o que favorece particularmente uma maior solubilidade dos complexos transportadores de $\mathrm{Au}$, até o momento que a razão $\mathrm{SO}_{4} / \mathrm{H}_{2} \mathrm{~S}$ torna-se elevada o suficiente para causar a desestabilização desses complexos (ver Fig. 10 de Cooke \& Simmons 2000).

CONCLUSÕES O estudo da paragênese do minério e da alteração argílica avançada, combinado com os estudos de inclusões fluidas, permitiu adicionar vários parâmetros que contribuem para uma melhor avaliação da gênese do depósito de $\mathrm{Cu}-\mathrm{Au}$ de alta sulfetação Golden Hill, com destaque para os seguintes aspectos:

1) Dois estágios de mineralização correlacionados com o desenvolvimento da alteração argílica avançada foram definidos: (i) estágio I com quartzo-caolinita-alunita-zunyita-diásporo-rutilopirita-enargita e, possivelmente, ouro sub-microscópico; (ii) estágio II com quartzo-natroalunita-pirofilita-pirita-enargita-luzonitafamatinita e ouro. No estágio I, em particular, a pirita com textura em frambóide é interpretada como de origem orgânica.

2) Essas assembléias indicam que o desenvolvimento da alteração argílica avançada e da mineralização de cobre e ouro ocorreram, em ambos os estágios, em ambiente de $\mathrm{pH}$ ácido $(<3)$ e oxidante, com valores de $\mathrm{fO}_{2}$ acima de aproximadamente $10^{-32,8}$ bar. As razões $\mathrm{SO}_{4}^{-} / \mathrm{H}_{2} \mathrm{~S}$ no ambiente da mineralização também foram elevadas $\left(f \mathrm{~S}_{2}>10^{-9,7}\right.$ bar), sendo aparentemente um pouco mais elevadas para o estágio II $\left(f \mathrm{~S}_{2}>10^{-8.7}\right.$ bar), em comparação com o estágio I. Temperaturas variaram entre $250^{\circ} \mathrm{Ce} 275^{\circ} \mathrm{C}$ para o estágio I e, provavelmente, atingiram acima de $280^{\circ} \mathrm{C}$ para o estágio II, devido à estabilidade de assembléias com pirofilita.

3) A ocorrência de minerais com W e Bi-Mo no estágio II, a variação na salinidade e temperaturas de homogeneização total das inclusões fluidas investigadas e a presença de $\mathrm{CO}_{2}$ no fluido sugerem um sistema hidrotermal com a interação progressiva de fluidos meteóricos, mais diluídos e frios, com fase vapor derivada da degaseificação de intrusões epizonais e/ou soluções magmáticas salinas e mais quentes, cenário que pode ser avaliado por meio de futuros estudos de isótopos estáveis.

4) Nessas condições físico-químicas, fluidos aquosos de salinidade baixa a moderada, conforme definidos pelas inclusões fluidas no estágio II, devem ter transportado o ouro e, possivelmente cobre, por meio de complexos do tipo metal-HS (e.g. $\mathrm{Au}(\mathrm{HS})_{2}^{-}$e $\mathrm{AuHS}_{(\mathrm{aq})}$ ), com deposição acionada pelo incremento significativo do potencial de oxidação do fluido até sua saturação, durante a contínua mistura de fluidos no sistema hidrotermal.

A presença de corpos intrusivos epizonais em profundidade tem sido apontada por dados geofísicos, podendo inclusive ter implicações na exploração mineral da região, com potencial para a ocorrência de mineralização de Cu-Au tipo pórfiro.

Agradecimentos Ao Conselho Nacional de Desenvolvimento Científico e Tecnológico (CNPq/Proc. $\mathrm{N}^{\circ} 132101$ - 1997-1) e ao Programa de Pós-Graduação em Geociências/ Área de Metalogênese do Instituto de Geociências pelo suporte financei-

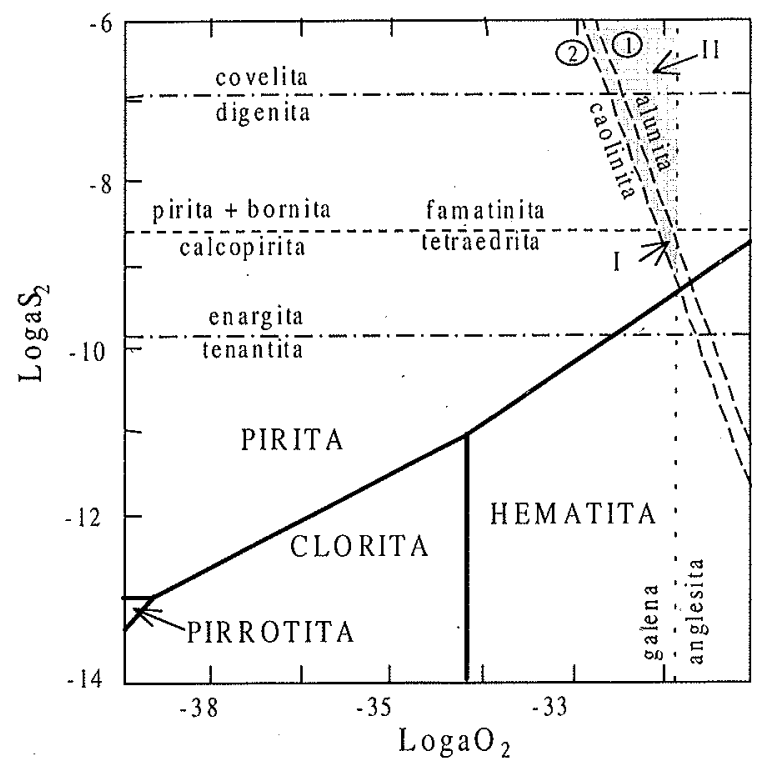

Figura 7 - Diagrama Log $a \mathrm{~S}_{2}-a \mathrm{O}_{2}$ mostrando os campos de estabilidade de minerais comuns em sistemas epitermais a $250^{\circ} \mathrm{C}$. Linhas sólidas delimitam os campos de estabilidade da pirita, pirrotita, clorita e hematita. Linhas tracejadas-pontilhadas representam reações entre sulfetos e sulfossais. Linhas com tracejados longos mostram os limites entre alunita e caolinita interpolados para soluções com salinidade 1 molal e razão $\mathrm{Na}$ $K=9$, considerando $I=$ concentração de enxofre $(\log \Sigma S)$ de 1,7 e $p H=2,8 ;$ e $2=\log \Sigma S$ de -1,0 e pH=3,5. O quartzo está presente como fase estável em todos os campos. Área pontilhada: estágio I; área quadriculada: estágio II. Adaptado de Heald et al. 1987.

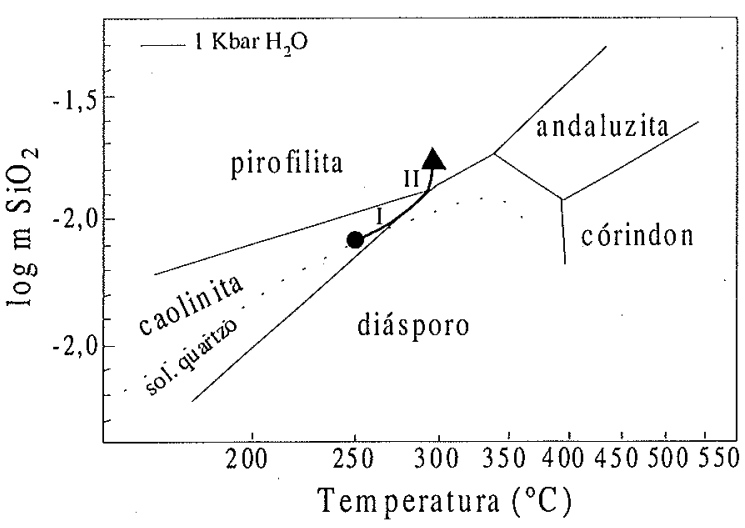

Figura 8 - Diagrama de estabilidade de minerais no sistema $\mathrm{Al}_{2} \mathrm{O}_{3}-\mathrm{SiO}_{2}-\mathrm{H}_{2} \mathrm{O}$, ̀̀ $\mathrm{PH}_{2} \mathrm{O}=1 \mathrm{~kb}$ ao longo da curva líquidovapor (Watanabe \& Hedenquist 2001).I = estágio I, II = estágio II

ro para o desenvolvimento deste estudo, o qual resultou a Dissertação de Mestrado do primeiro autor. $\grave{A}$ associação MacDonald Mine Exploration Ltd \& Geominera S.A. pelo apoio a esta investigação, permitindo o trabalho de campo, obtenção de amostras de furos de sondagem e acesso aos dados; a Reiniel Lugo e Eugenio Escobar da Empresa Geólogo Minera, Camagüey, Cuba que traba- 
lharam no projeto da Companhia MacDonald Ltd. Aos pesquisadores do Instituto de Geología y Paleontología Dr. Bienvenido Echevarría, Dra. Lilavatti Diaz de Villalvilla, Maria Santa Cruz
Pacheco, Bienvenido Palácios, por seus conselhos no trabalho de campo, informações e outros apoios. Aos revisores da RBG pelas sugestões ao manuscrito.

\section{Referências}

Benning L.G. \& Seward T..M. 1996. Hydrosulfide complexing of $\mathrm{Au}$ (I) in hydrothermal solutions from 150 to $400^{\circ} \mathrm{C}$ and 500 to 1500 bars. Geoch. Cosmoch. Acta, 60:1849-1871.

Capote C. 1999. Análise do controle estrutural metalogênico em Cuba centro-oriental, com base em dados integrados. Instituto de Geociências, USP, São Paulo, Tese de Doutoramento, 222 p.

Cabrera R., Kramer J.L., Pantaleon G. 1984. Vinculación del magmatismo y los yacimientos meníferos de Cuba con los procesos tectónicos. Ciencias de la Tierra y del Espacio, 9:47-58.

Cooke D.R. \& Simmons S.F. 2000. Characteristics and genesis of epithermal gold deposits. In: S.G. Hagemann \& P.E. Brown (eds.), Gold in 2000. Reviews in Economic Geology, 13:221-244.

Echevarría B., Talavera C.F., Tchounev D., Iordanov I. 1986. Petrografía y geoquímica de las vulcanitas de la región Guáimaro-Las Tunas (Cuba). Ciencias de la Tierra y del Espacio, 11:27-35.

England B.M. \& Ostwald J. 1993. Framboid-derived structures in some Tasman fold belt base-metal sulphide deposits, New South Wales, Australia. Ore Geology Review, 7:381-412.

Escobar E., Roque F., Stanek K., Balvis C., Pérez J., García A., Jiménez L., Pereira F. 1988. Proyecto de búsqueda orientativa y detallada de metales básicos y nobles en la zona Vidot-Siboney. Empresa Geólogo-Minera Camaguiey. (inédito). Fondo Geológico Nacional, Habana: $221 \mathrm{p}$.

Green D. 1996. Alteration mapping, petrography and X-ray diffraction studies. MacDonald Exploration Ltd \& Geominera S.A., Cuba. (inédito).

Hanningtong M.D., Poulsen K.H., Thompson J.F.H., Sillitoe R.H. 1997. Volcanogenic gold and Epithermal-Style Mineralization in the VMS Enviroment. In Barrie, C.T.; Hannintong, M.D. (eds) Volcanic-Associated Massive Sulfide Deposits: Process and Examples in Modern and Ancient Settings. Short Course. Carleton University, Ottawa, Ontario, 183-212.

Heald P., Foley N.K., Hayba D.O. 1987. Comparative anatomy of volcanic-hosted epithermal deposits: acid-sulfate and adulariasericite types. Economic Geology, 82:1-26.

Hedenquist J.W.\& Henley R.W. 1985. The importance of $\mathrm{CO}_{2}$ on freezing point measurements of fluid inclusions: evidence from active geothermal systems and implications for epithermal ore deposition. Econ. Geol., 80:1379-1406.

Hemley J.J., Hostetler P.B., Gude A.J., Muontjoy W.T. 1969. Some stability relations of alunite. Econ. Geol., 64:600-612.

Hemley J.J., Montoya J.W., Marinenko J.W., Luce R.W. 1980. Equilibria in the system $\mathrm{Al}_{2} \mathrm{O}_{3}-\mathrm{SiO}_{2}-\mathrm{H}_{2} \mathrm{O}$ and some general implications for alteration/mineralization processes. Econ. Geol, 75:210-228.

Knight J.E.1977. A thermochemical study of alunite, enargite, luzonite, and tennantite deposits. Econ. Geol., 72:1321-1336.
Kramer L.J., Poznaikin V.V., Morales A., Echevarría B.T., Rodriguez R., Cañete C.C. 1990. Fundamentación de los trabajos de búsqueda de oro en el território de la República de Cuba, com la evaluación de los recursos pronósticos a escala 1:500000. Instituto de Geología y Paleontología (IGP), Ministério de la Industria Básica, Habana (inédito). Arquivo do IGP.

Melling D.R. 1998. Qualifying report on the Florencia-Jobabo concession and The Florencia Sector Camaguiey and LasTunas Provinces, Republic of Cuba. MacDonald Mines Exploration Ltd. Relatório disponível somente em http//www.macmines.com/ geoapril.html.

Muntean J.L., Kesler S.E., Russell N., Polanco J. 1990. Evolution of the Monte Negro acid sulfate $\mathrm{Au}-\mathrm{Ag}$ deposit, Pueblo Viejo, Dominican Republic: important factors in grade development. Econ. Geol., 85:1738-1758.

Ovchinikov V., Díaz G., Bolotov R., Valkov V., Biriolin V. 1983. Informe de los trabajos de búsqueda orientativa y detallada en la región Martí-Tunas. Empresa Geológica de Camaguiey. Centro Nacional Fondo Geológico. (inédito): $450 \mathrm{p}$.

Pérez M. \& Sukar K. 1997. Granitóides del Arco Volcánico Cretácico de la región Central de Cuba (antigua província de Camagiiey). In Furrazola G. \& Cambra K.(eds.) Estudios sobre geología de Cuba. Centro Nacional de Información Geológica, Habana, pp.388-398.

Pérez P.E., Pimentel O.H., Pardo E.M., Lugo P.R. 1998. Interpretación tectónica estructural de los datos geofísicos en la región Ciego de Ávila-Camagüey-Las Tunas. (inédito)Arquivo do IGP,

Roedder E. 1984. Fluid Inclusions. Reviews in Mineralogy. Mineralogical Society of America, 12:12-45.

Rickard D.T. 1970. The origin of framboids. Lithos, 3:269-293.

Schneider H.J., Özgür N., Palácios C.M. 1988. Relationship between alteration, rare earth element distribution and mineralization of the Murgul copper deposit, Northwestern Turkey. Econ. Geol., 83:1238-1246.

Shevchenko I.A., Bello D. V., Dovnia A., Santa Cruz G.J., Lugo P.R., Eguipko O., Frolov V., Burov V. 1976. Informe del levantamiento geológico a escala 1: 100000 en la región de Martí-Victória de Las Tunas. CNFG, Habana.

Velinov I., Gorova M., Tcholakov P., Tchounev D., Ianeva I. 1983. Secundary quartzites developed after cretaceous volcanic from Zaza Zona, Cuba. Sófia, Rev. Geol. Balcânica, 13(6):53-68.

Watanabe Y. \& Hedenquist J.W. 2001. Mineralogic and stable isotope zonation at the surface over the El Salvador porphyry copper deposit, Chile. Econ. Geol., 96:1775-1797.

Manuscrito A-1152

Recebido em 06 de abril de 2000

Revisão dos autores em 10 de maio de 2003 Revisão aceita em 15 de maio de 2003 